\title{
Teacher Perspectives on Language Learning Psychology
}

\begin{abstract}
Research into the psychology of language learning has grown exponentially in the last decade, yet, teacher perspectives on the field have been surprisingly absent from this body of research. The present study was designed to address this gap. Drawing on a survey with 311 foreign language teachers working at different school levels in three European countries, and on individual, semi-structured interviews with 11 teachers, the study focuses on the psychological aspects of language learning which teachers felt were particularly important in their own settings. In particular, teachers' beliefs, experiences and teaching strategies were explored. The data also revealed strong interconnections between language learning psychology constructs, differences across contexts, and a perceived link between learner and teacher psychology.
\end{abstract}

Keywords: language learning psychology; teachers; beliefs; practices; teacher psychology

\section{Introduction}

Earl Stevick famously stressed the importance for successful learning and teaching of understanding what is happening 'inside and between the people in the classroom' (Stevick 1980: 4). As Williams et al. (2015: 1) argue, a knowledge of psychology is "invaluable in helping us to generate the best possible learning conditions in our language classrooms". Thus, although a confident knowledge of teaching methods and a good set of teaching materials or tools are important, without an appreciation of the psychology of learners and ourselves as teachers, we will not be in a position to make the best use of these tools and resources. As a result, the three authors of this article share this conviction in the centrality of psychology for an appreciation of how, why and what people learn in respect to language learning. Recent years have seen a proliferation of monographs and research papers covering a multitude of areas within this field (e.g. Dörnyei and Ryan 2015; Gkonou, Tatzl and Mercer 2015; Gregersen, MacIntyre and Meza 2014; MacIntyre and Mercer 2014; Mercer, Ryan and Williams 2012; Williams, Mercer and Ryan 2015); however, as yet, very little empirical research has been done to establish what teachers' perspectives on this field are. Fundamentally, teachers' beliefs influence their teaching practice and decision-making processes, and ultimately strongly determine the nature of classroom life and the overall classroom atmosphere (Borg 2003, 2015; Kalaja et al. 2016). This means that teachers' perspectives are important to understand how the psychology of classroom life, relationships 
and interactions unfold. Therefore, this study set out to explore teachers' beliefs about, experiences with and practices in respect to key areas of language learning psychology (LLP).

In this paper, we begin by outlining developments in the field and considering the perspectives gained in the area and their perceived relevance for language teaching practices. We then reflect on the importance of teacher perspectives to validate such insights and the need for understandings situated in actual classroom experiences. The main part of the paper describes a two-stage research study conducted with teachers from across Europe in establishing their perspectives on LLP. The discussion then focuses on reflecting on our findings in respect to the established literature and highlighting perceived differences in perspectives. We conclude by proposing possible next steps, which we hope will ensure that the field integrates teacher perspectives in its development and remains grounded in the actual practices of real language classrooms.

\section{Literature review}

\section{Language learning psychology}

In this article, we define LLP as, 'the mental experiences, processes, thoughts, feelings, motives, and behaviours of individuals involved in language learning" (Mercer et al. 2012: 2). As a field of study within applied linguistics, it has been undergoing a series of developments and changes and has gradually been gaining a sense of community and identity emerging from key publications (Dörnyei and Ryan 2015; Gkonou, Tatzl and Mercer, forthcoming; Gregersen, MacIntyre and Mercer, forthcoming; Williams, Mercer and Ryan 2015), a biannual conference, which began in 2014, and several journal special issues (Mercer and Ryan 2015a, b). Traditionally, the field has been dominated by motivation with other constructs receiving much less attention and/or developing their own independent domains of study, such as autonomy, strategies, and beliefs. However, the field has become more interconnected and researchers are more consciously exploring the links between the different areas and constructs in LLP. Concurrently, less commonly researched constructs and areas such as willingness to communicate (WTC), attributions, and emotions have also begun to gain more attention within the context of the wider community of LLP researchers, thereby broadening the profile of the field. Other developments include the introduction of Dörnyei's L2 self system of motivation (2005), which has led to an increased flurry of research on self and identity in respect to both learners and teachers (see, e.g. Hiver 2013; Kubanyiova 2014; Mercer and Williams 2014). Generally, the field of LLP has tended to focus primarily on the psychology of learners with relatively little attention paid to the psychology of teachers, with 
the exception of research into teacher identities and cognitions (Borg 2015; Clarke 2008; Varghese et al. 2005), and, more recently, teacher motivation (Dörnyei and Kubanyiova 2014). These changes and developments have meant that the field has become more complex and now covers a wider range of constructs than traditionally has been the case.

As an applied discipline, we believe that research should connect with and represent practice as best as it can and ideally should be perceived as relevant for practitioners and not just academics. As researchers in this area, the authors have had differing experiences with teachers' responses to LLP ranging from their perception of this field as perhaps the most critical dimension of being a language teacher given the social and interactional character of language learning, to those who feel that methods and materials are much more important with LLP of only peripheral importance. Driven by a wish to appreciate the relevance of our own work for teachers, who along with their learners are often the intended end beneficiaries of our research, we decided it was important to bring in their voices and perspectives on the field. Our aim is to better understand how teachers view and define LLP, what their priorities are in this regard, and how they engage with these issues on a daily basis in their respective teaching contexts.

\section{Importance of teacher perspectives for classroom practice}

It is generally widely accepted that teachers' beliefs and cognitions (Borg 2003, 2015) affect their professional practice and, indeed, 'everything that they [i.e. the teachers] do in the classroom' (Williams and Burden 1997: 56-57). Similarly, research has shown that teacher practices can also inform their belief systems and the two are best considered as being mutually informing (e.g. Breen et al. 2001; Burns 1992; Johnson 1992; Li 2013; Phipps and Borg 2009). Clearly, both teacher beliefs and practices define and shape the nature of life in the classroom as well as the opportunities that learners are afforded. Given the importance we assign to LLP and its centrality in classroom life, it is crucial to understand what teachers believe LLP entails and how important they feel it is. To the best of our knowledge, there has been very little research on teacher beliefs about LLP with isolated individual exceptions such as Dörnyei and Csizér's study (1998) on language teacher beliefs about motivational strategies, Golombek's work (1998) on various tensions language teachers face in the classroom, and Borg and Al-Busaidi's investigation (2012) of English language teachers' beliefs about and practices with learner autonomy.

\section{Methodological design}




\section{Aims of the study}

The aims of this study are to explore teachers' perspectives on LLP. Principally, the first part of the study was designed to establish which aspects of LLP teachers from a range of contexts feel are priorities in their settings. The research questions for this stage of the study were:

- Which aspects of LLP do teachers feel are especially important and relevant for their setting?

- Are there any differences in teacher priorities according to school level (e.g. primary, secondary and tertiary)?

The second part of the study was designed to build on the insights gained in part one by focussing on teachers at the secondary school level and exploring in more detail their perspectives on the five key areas which emerged from part one. Specifically, the research questions addressed by this stage are:

- What do teachers believe are important in respect to psychology in the language classroom?

- Specifically, what do they know and believe about the constructs highlighted in part one?

- What experiences have they had in respect to these constructs?

- What are their teaching practices in respect to them?

- What other strategies and approaches do they have in respect to psychology in the language classroom?

\section{Data collection tools}

\section{Stage one: Questionnaire}

The questionnaire was designed to establish what areas of LLP teachers felt were their priorities in their language classrooms. To this end, an online questionnaire was constructed using Survey Monkey and the link along with an accompanying letter was sent to teachers at all educational levels in Greece, Portugal and Austria. The questionnaire began with a basic biodata section. The main part of the questionnaire comprised 14 items about key constructs from LLP, which were selected based on the content of two recent handbooks in the field (see Dörnyei 2005; Mercer et al. 2012). The following 14 constructs were included in the questionnaire based on key constructs from the field as represented in Mercer at al. (2012): self-concept, personality, motivation, mindsets, attributions, foreign language anxiety, willingness to communicate, learning styles, learning strategies, metacognition, goals, learner 
autonomy, group dynamics, and emotions. To ensure the constructs were understood by the participants, a brief definition was offered alongside each term. The participants were then asked to rate on a seven-point Likert scale how important they believed each of these constructs is for their particular teaching context. A final open-ended section asked the teachers to then list which two of these constructs were most important for them and explain why they felt this. Once the questionnaire was completed, a pdf file comprising an annotated bibliography about useful books for teaching practice on some of these constructs became accessible and it was hoped that this would ensure some benefit and reciprocity for the participants.

\section{Stage two: Interviews}

The second part of the study involved semi-structured interviews conducted with volunteer teachers from secondary schools in the three countries at the centre of this study. An email was sent asking for volunteers and outlining the study and its purpose. Those who agreed to take part were then provided with an information sheet about the interview process including a consent form, which they signed. All the interviews followed the same basic protocol. Specifically, the interviews opened with a set of questions on understanding the participants' backgrounds and teaching contexts such as their qualifications, their journey towards language teaching, a brief description of their current working context, and their views on good language lessons and language teachers. This section was then followed by specific questions about LLP and the seven constructs. These questions centred on the interviewees' own definitions and understandings of the terms, their positive or negative experiences with these LLP aspects in their classrooms, possible interconnections among the constructs under discussion and explicit questions on how they address aspects of LLP in their daily practice. However, at the same time, the design was left deliberately open, in order to enable the interviewer to react responsively and flexibly to the flow of the individual conversations, whilst mindful of covering the approximate same content across the settings. In the reporting of the interviews, all names and specific place names have been changed to protect the identities of the participants who have also been assigned pseudonyms. The participants in each setting were thanked with a small gift for their time and have been promised a copy of the finished report.

\section{Participants and contexts}


The data generated in this study stemmed from three central and southern European countries: Greece, Portugal and Austria. These countries represent the main working contexts of the three authors, who were keen to understand their local realities and working contexts better. The three researchers felt better able to interpret regional and local concerns and particularities, as will become clear below in the analysis of the interview data. However, it was also felt that these three countries represented some of the diversity across Europe. In part one of the study, it was decided to generate data with a wider population of teachers across educational settings, in order to establish whether priorities in this respect differed across settings. A total of 311 teachers participated in the first phase of this project. Their mean age was 41.03 years old. Table 1 summarises the demographic information for participants in terms of their gender, country where they currently teach, level of teaching and teaching experience.

Table 1. Participants' demographic information

For part two of the study, it was then decided to focus on secondary school teachers who represent the majority group of language educators in compulsory education contexts across the globe and the largest population in phase one of this study. Each of the researchers wrote emails to personal and national networks seeking volunteers to participate in interviews. 11 teachers were interviewed by the researchers: three working in Greece, four in Portugal and four in Austria. Table 2 summarises the biodata for all interviewees.

Table 2. Biodata for teacher interviewees

\section{Data analysis}

\section{Questionnaire}

Quantitative data. The Likert-scale questionnaire items were analysed using SPSS version 19.0. Descriptive statistics were used to represent teachers' priorities with respect to the LLP constructs in their own settings and also according to the three school levels. Given that the first research question for the first stage of the project was intended to identify those aspects of LLP that teachers thought were particularly important and relevant for their own settings, for data analysis purposes, we cumulatively calculated the number of teachers who have rated LLP items as extremely important and important. 
Qualitative data. The open-ended questionnaire data were analysed by two of the researchers separately using Atlas.ti. There were 127 answers to the open-ended question, which included a total of 7,153 words. Two researchers looked for key psychological themes as well as any other salient topics emerging from a more inductive coding procedure. Once each researcher had coded the data, each set of codes was compared together to check the categories and look for omissions, disagreements and overlap. All three researchers then discussed the emergent codes and themes, which also provided the basis for the construction of the interview guide.

\section{Interview data}

In respect to the interviews in part two of the study, all of the data were transcribed digitally for coding using the data management software Atlas.ti. This generated 95,305 words. Then two members of the research team each separately coded and analysed the data in a grounded manner allowing themes and unexpected topics to emerge and without using a pre-defined set of codes or theoretical framework. Once both researchers felt their coding processes had reached 'saturation' (Charmaz, 2006), they exchanged their completed coding lists and memos and discussed where they saw similarities, differences and patterns. Based on the discussions, the codes and memos were assimilated and one of the researchers then wrote a first draft of the analysis. This was then checked and amended as appropriate by the second researcher who had also been coding the qualitative data. The third researcher who was also familiar with the transcripts also checked the analysis to confirm its representation of the transcribed interviews.

\section{Findings}

\section{Questionnaire data}

\section{Teacher priorities}

Perhaps unsurprisingly, participating teachers at all educational levels rated motivation as the most important LLP construct in their own settings. Motivation was followed by willingness to communicate, emotions, group dynamics and self-concept. Table 3 shows the numbers of teachers who have rated the 14 LLP constructs as ' 1 ' (i.e. extremely important) and '2' (i.e. important) as well as the total number of teachers who rated the items as extremely important and important $(N=311)$. The five priorities for teachers are printed in bold. Also, the numbers in parentheses in the final column of Table 3 indicate the order of importance of the five most prominent constructs for teachers. 
Table 3. Numbers of teachers who rated the LLP constructs as important and extremely important

\section{Differences according to school type}

The questionnaire data were also analysed in terms of teachers' priorities according to three different school types, namely, primary school, secondary school and tertiary education. Table 4 indicates which LLP constructs were rated as most important by teachers at each school level.

Table 4. Differences in priorities according to school type

As is evident from Table 4, there were some clear similarities but also some interesting differences in teacher priorities across the three settings. Irrespective of school type, motivation was viewed as the most important construct in all three teaching contexts. Emotions and group dynamics were two other constructs that featured among all teachers' LLP priorities regardless of the school level they were teaching in. Specifically, primary school teachers rated emotions as equally important as motivation. They also felt that selfconcept was the second most important construct in primary school classrooms, as opposed to secondary school teachers for whom learners' WTC was the second most important psychological variable following motivation. In fact, self-concept did not feature at all among secondary school teachers' top five priorities in their teaching. Interestingly, teachers in secondary schools were the only group that rated learning strategies as important in their contexts. Finally, with reference to teachers in post-secondary education, self-concept and willingness to communicate were rated as equally important, as were learner autonomy and group dynamics.

\section{Additional insights from qualitative questionnaire data}

The open-ended question confirmed the key constructs that teachers felt were important. However, the data also raised some interesting themes that we were keen to explore more in the interviews. As noted above, 127 teachers responded to this open question. Out of this sample, 76 teachers merely listed the two most important constructs in their context without explaining why they believe they are important. Of the remaining 51 more elaborate answers, we have noticed certain common patterns, which we present below. 
Most notably, 17 out of the 51 teachers who responded more fully to this section appeared very aware of the interconnections between various facets of learner psychology as they linked together various constructs in their responses. For example, Teacher 38 argued that 'some aspects [of LLP] kind of mutually influence each other', , referring to motivation, emotions, self-concept and language anxiety. However, the focus of the connections they made appeared to be quite individual with no notable patterns of specific connections emerging across the responses.

On the whole, 13 teachers also drew attention to the perceived importance of the group atmosphere and the general emotional climate in the class at the level of the class as a whole, not just in respect to individual learners. The extract below illustrates this point:

When students feel secure and valued within a group they are more likely to be more active, engaged and less anxious. (Teacher 109)

15 teachers also seemed to have certain fixed ideas about their role with respect to their learners' psychology in the classroom and specifically about motivation. As Teacher 7 explained, 'contrary to what some parents think, a teacher cannot motivate students, only try to provide the circumstances in which students can motivate themselves'. Teacher 183 also added: 'So when a student has an accurate picture of his performance and is determined to succeed by working on any weak points and does not give up, then, along with his teacher's guidance, he will manage to succeed'.

\section{Interview data - Teacher experiences, beliefs \& practices}

The analysis of the interview data revealed complex and interesting insights regarding teacher perspectives on LLP, which extended and provided a more nuanced view on the findings from the questionnaire data. We have grouped the key findings into five main areas although there is naturally overlap between these sections.

\section{Beliefs about what LLP is}

All the teachers had beliefs about what they felt LLP is, although they differed in the degree of certainty with which they held these beliefs. There was some uncertainty for four teachers who explained that they were unsure about what it is. For many $(N=8)$, they saw LLP as being connected to the brain and neuroscience. For instance, Teacher Gr1 defined LLP as 'the psychology surrounding a brain that is trying to learn, that is trying to acquire information and put it in practice which is quite complicated'. In referring to their own teacher training, 
three teachers explained that they had not had any input on psychology in any form, whereas four explained they had had some psychology in their training, primarily educational or developmental psychology. However, eight teachers explained that they mostly relied on their intuition and teaching experience in order to deal with different aspects of LLP in the classroom. Teacher Pt4's quote is indicative of this point:

Pt4: Because all we do is on a basis that you think it's correct you think it's the right thing but you are not sure ok? You are doing it intuitively ok?

Interviewer: Based on your experience maybe?

Pt4: Yes, more like that.

\section{Specific constructs}

In terms of the specific psychological constructs that we wished to explore in more detail, there were some interesting nuances to extend the questionnaire data. Most notably, motivation was the most salient construct in the data for all the teachers; however, for two teachers, they went further and in fact appeared to equate motivation with psychology. As Teacher Gr1 explained,

There is nothing that can replace motivation. Those who are not motivated can never accomplish anything. There is no way to replace motivation and still have successful learning of any kind, even driving. Not only language learning, even managing to get hold of a job and keep that job. Everything is motivation.

Other salient constructs mentioned as important by the teachers were emotions, confidence, group dynamics, teacher/learner rapport and autonomy. Interestingly, two of the participating teachers appeared to equate autonomy with working alone and confidence was equated by three teachers as being the same as self-concept. A construct that emerged from the interviews but was a lot less prominent in the questionnaire data was personality as many teachers $(N=8)$ emphasised the uniqueness and individuality of learners, the need for learnercentred approaches and how different learner personalities affected approaches to teaching, learning and group dynamics. In particular, several teachers felt that extroverted learners find learning a foreign language easier (Aus1), are more willing to communicate (Gr3, Pt3), have different approaches to perceiving and evaluating their own competence in the language $(\mathrm{Gr} 3$, $\mathrm{Pt} 2$ ), and are more confident (Pt2) and more willing to work in pairs/groups in class (Pt3). 
Also, teachers reported that different learner personalities determine their own approaches to error correction. As Teacher Pt2 explained,

The student who is normally shy and doesn't want to get into the public and if she is making a lot of mistakes and she is there making an effort trying to communicate and she is getting into it I won't stop her and at the end I will correct it but if it's that huge self-confident student who is always eager to show off their proficiency in English and he makes this huge mistake yes I will stop him immediately.

Obviously, our questioning guided the responses towards constructs emerging from the questionnaire data as important. However, all the teachers also steered the interviews drawing attention to those dimensions they felt were especially important. Facets such as strategies and styles, or identity and culture, or mindsets and attributions were completely absent from the data. Whilst being careful not to draw any conclusions from this, their absence was perhaps surprising, at least in the case of identities and strategies, which have both received considerable attention in the research literature. However, as noted above, there may also be differences according to educational levels and all the teachers in the interviews were working in secondary contexts.

\section{Contextualisation}

A notable dimension in the data is how the different countries seemed to draw attention to different levels of cultural contexts and this was where the researchers' context-sensitivity was beneficial. In the case of Greece and also albeit to a lesser extent Portugal, the economic crisis and state of the educational system as a whole was referred to repeatedly throughout the data. Two of the Greek and three of the Portuguese teachers discussed the perceived effects on classroom life and teaching of developments in national and macro level culture. Extracts referring to the socio-economic crisis surfaced repeatedly in the interviews:

Hopefully I would like my country to be out of this financial crisis which will impact a lot, because there are many problems that, there are many problems that have influenced teaching in Greece mainly because of the financial crisis. (Grl)

I sometimes would like to have more how can I say help from the government to give me more quality inside the classroom [...] then you have this aspect that is forced by the national 
agency national government which is money and money is being taken off every month and teachers are getting more and more demotivated.(Pt2)

In contrast, Austrian teachers focused more on their specific schooling contexts referring instead more to the influence of the particular characteristics of their school, rather than any national level influences, such as this example from a teacher in a private school:

I think we have an ideal mix of students, from the lower class up to the upper middle class up to, we call it upper class. On the other hand, we also have a lot of students, and that is the other side of the coin, lots of students that have been, we call it, handed over from one school to another because they are quite problematic, which means if you pay for the school, they will accept you and give you another chance. These are the two sides of the coin and they can be quite disruptive and quite problematic. (Aus4)

All teachers frequently discussed the importance of the classroom culture, nature of group dynamics and the importance of good working relationships in class, especially in terms of the quality of the rapport between teacher and learners:

Always things will be okay to people to the extent that they don't feel threatened, okay? The environment should be nice and then they should feel comfortable with you and their fellow students. (Gr3)

Some of the facets of these group dynamics and rapport strongly resemble characteristics of emotional intelligence (such as empathy and social skill) and draw attention to the role this plays for teachers in managing classroom life, even if the teachers here do not refer to this term explicitly in these data. Three teachers also highlighted the importance of affective selfregulation, which is another component of emotional intelligence, by explaining that negative emotions should be kept outside of class. Teacher Pt3 explained:

Emotion is the key well it's not the key it's one of the keys if you want if you are in a good mood if you can transmit them you are happy that things are going to work ok then the class is going to work ok and if you have different emotions today they feel it cause they know you and they feel something's wrong with you even if you have problems with your family well the teacher should be pretty much like a clown you know don't bring your problems to class of course sometimes you can't help it but don't bring your problems to the class because you are going to get emotional in a bad sense and then things are not going to work properly. (Pt3) 


\section{Teaching strategies}

All the teachers had strategies for attending to LLP in class in whatever form. Here it became apparent that teachers' own experiences and their intuition stemming from these played the central role in how teachers dealt with classroom life and LLP. The teaching strategies mentioned by teachers included making learning personally relevant $(N=9)^{2}$, being careful not to over praise the students $(N=7)$, trying to reach students as individuals $(N=6)$ and diversifying the lesson/class $(N=4)$. Table 5 summarises these strategies and includes an illustrative quote for each strategy from the interviewees.

Table 5. Key strategies for LLP reported by teachers

Teachers also appeared to generate an idea of 'prototypical learner types' based on their past experiences. They used these as a frame of reference to guide how they interact with and work with individual learners who they often classed in terms of these 'types' of learners. As Teacher Gr3 explained,

I think one of the toughest things in my job is to challenge students' beliefs. For example, I have a student currently, he is convinced that teaching listening is having the teacher doing the DJ, you know, playing the listening one after the other and he will write $a, b, c$. And because I don't play any recordings during the class, he is displeased and he says 'More, more, I want more listening', because this is what he believes, because if we don't play any recordings in the classroom we don't do much listening, teaching and practice. So you can't teach strategies to this person. First you have to challenge his beliefs, make him see things from different eyes, from a different point of view, explain to him the purpose of doing a listening class.

An interesting dimension across teachers was differences concerning the reported degree of control that they felt they had over learner psychology. Three teachers felt there was little they could do to control or influence aspects of learners' psychology, such as motivation. Teacher Aus1 argued:

I don't have a recipe for motivation [...] And I think you can't motivate children, but you can do much more to demotivate children. [...] it's so difficult for you to foster motivation. (Aus 1) 
In contrast, the remaining eight teachers felt that only they could (and should) be responsible for influencing and controlling learner psychology:

Therefore, unless I in-build motivation, unless I think pleasure, safety, some sort of personal investment, there is not going to be any success out of my teaching. (Gr1)

Motivation comes from the teacher, not from the kids any more. (Aus3)

\section{Teacher psychology}

Finally, a striking feature of the data was how teachers often mentioned how they felt, their confidence, emotions, moods, motivation etc, thereby recognising the importance of their own psychology for classroom life generally and specifically also for learner psychology. Talking to the teachers made us aware of the importance of healthy teacher psychology not only for the teachers themselves but also for their learners. The following quote illustrates this issue:

If you are confident, they [i.e., the students] trust you [...] confidence is giving students a hint for them to feel good but first you have to feel good about what you are doing. (Pt2)

Teachers also stressed the importance of positive group dynamics and collaboration among teachers on different fronts. As Teacher Gr1 explained,

Schools don't do much to support their teachers. There is an even, I feel that very often teachers in Greek foreign language schools are like ships sailing in the sea. They might not be crashing but they are not communicating. They are not collaborating. We talk about pair work in class. What about pair work in the staff room? What about peer observations? What about peer lesson design? What about sharing the activity of the month during every meeting?

\section{Discussion}

The findings point to a series of interesting dimensions worthy of reflection for the field as a whole. The first concerns the priorities of research in comparison with the priorities of teachers. Whilst there is much overlap, there are also some surprising differences. For example, group dynamics featured prominently across educational levels and in the interview data, yet, with a few notable exceptions (Dörnyei and Murphey 2003; Murphey et al. 2012), it remains notably under-researched. This suggests that whilst teachers acknowledge the importance of understanding and teaching to the whole group, the learner-centred approaches 
dominating academic discourse may have led to a focus on the individual learner, and thus the subsequent neglect of the nature of the group and collective psychologies and dynamics. Personality is another construct that teachers emphasised usually in connection with the perception of each learner as a unique individual. This was the construct that teachers most frequently connected with other aspects of the learners' psychology. Whilst there has been some quantitative work based on the big five (Dewaele and Stavans 2014; Dewaele and AlSaraj 2015), it too remains comparatively under-researched and in need of exploration from a wider range of empirical approaches.

The data also show that there are some misunderstandings about the field of LLP generally but also specific constructs in the field. Most of the interviewees associated psychology only with neuroscience and reported knowing little or nothing about educational or social psychology. Further, they claimed to have had little or indeed no input or training in this area. For some, in fact, the scope of the field was limited merely to motivation. The data appear to imply that the scope and depth of teachers' understandings about the field are somewhat limited. Teachers also misunderstood the nature and dimensions of key terms such as confidence or autonomy. This suggests that teachers could potentially benefit from more training in aspects of social and educational psychology as relevant to language learning to broaden their knowledge base and nuanced understandings of the complexity of LLP in the language classroom. However, the data also revealed that teachers have considerable knowledge, expertise and sensitivity to aspects of the psychology involved in language learning. Based on their experiences, the teachers built upon an intuitive knowledge base and formed prototypical understandings (see Berliner 2001) on which they based their decisionmaking in regard to various psychological aspects of classroom life. An ideal next step would be to find ways to combine research knowledge and classroom-based experiential expertise in order to support further research but also other teacher training designs. In particular, it would be worth examining the kinds of prototypes teachers have formed and how they utilise these frames to understand the psychology of their learners and their groups (cf. Berliner 2001).

A finding that surprised us given our explicit focus on learner psychology was the emphasis by interviewees also on their own psychology. Research has shown (Dörnyei and Kubanyiova 2014; Tassinari 2015) that teacher and learner psychologies are inextricably linked and indeed may best be thought of as two sides of the same coin. Yet, the research in the field focuses predominantly on learner psychology with only a few notable exceptions and not nearly the same breadth and depth of research regarding teacher psychology as is available in respect to learners. Clearly, the research agenda needs to be expanded to also 
investigate teacher psychology to the same degree of complexity as has been devoted to learner psychology. Perhaps more importantly is also the need for research that examines the relationship between teacher and learner psychologies in the language classroom to see in what ways these may be mutually defining.

Finally, an interesting dimension of the data was how teachers seemed to be highly sensitised to the local conditions and the context-sensitive nature of learner and teacher psychologies. They also displayed a sophisticated awareness of the interconnections between multiple facets of psychology and how they interrelate with each other beyond a surface suggestion of interconnections as possibly prompted by the questions in the interview. Clearly, if researchers wish to communicate with and make their research findings relevant for teachers, they will need to do so in a manner which acknowledges the complex, interconnected and socially situated character of psychology which teachers intuitively recognise from their daily teaching lives.

\section{Conclusions, limitations and implications}

This study was an initial attempt to explore teachers' perspectives on the field of LLP. It was only a small-scale study with a limited number of participants, across only three European countries, focusing primarily on the secondary school level. Nevertheless, it has raised some interesting questions for researchers, especially those wishing to reflect on the applied nature of their work, as well as for teacher training programmes in this area.

The research agenda in LLP has been defined in the past at least by dominant experimental and behaviourist paradigmatic approaches and designs. However, growing interest in complexity perspectives in LLP suggest the field is well placed to engage with the complexity and situatedness of psychology as teachers appear to understand it. It also means the field is better placed to engage with group dynamics in terms of systems thinking or to look most closely at interrelations such as between the teachers' and leaners' psychologies.

In practical terms, there would seem to be a gap with the research that has been conducted and teachers' understandings and evaluations of this field. Many teachers have developed their own strategies for coping with various aspects of classroom life. Yet, there remain a range of issues, constructs and concepts that teachers have little awareness of or which they may also have misunderstood. It suggests that both teachers and learners could benefit from further training in this area to broaden their understandings but also to support them with practical additional strategies to complement those they already use. Especially in the area of initial teacher education, it would be helpful to provide student teachers with 
explicit strategies for managing the psychologies at play in the language classroom, rather than leaving it to time and experience for them to develop their own experiential knowledge as these teachers have done.

Naturally, as authors, we feel that LLP is a central dimension of successful language learning and one that is highly practical and relevant to daily classroom life. The teachers in this study seem to agree, but do so in different ways. We feel that following this first step, the field could benefit from engaging more deeply with teacher perspectives. Firstly, researchers could learn from the real-world knowledge, experience and strategies employed by language teachers in their daily lives. Secondly, academics could reflect more fully on what they feel they can share and add to teachers' experiential knowledge in ways that resonate and appear relevant and practicable. We hope this study can in some small part contribute to enhancing the dialogue between teachers and researchers in this field opening up pathways for each side to learn from the expertise of the other.

\section{References}

Berliner, D.C. 2001. Learning about and learning from expert teachers. International Journal of Educational Research 35, no. 5: 463-482. doi:10.1016/S0883-0355(02)00004-6

Borg, S. 2003. Teacher cognition in language teaching: A review of research on what language teachers think, know, believe and do. Language Teaching 36, no. 2: 81-109. doi: $10.1017 / \mathrm{S} 0261444803001903$

Borg, S. 2015. Teacher cognition and language education: Research and practice. London: Bloomsbury.

Borg, S. and S. Al-Busaidi. 2012. Learner autonomy: English language teachers' beliefs and practices. ELT Research Paper 12-07. London: British Council.

Breen, M.P., B. Hird, M. Milton, R. Oliver and A. Thwaite. 2001. Making sense of language teaching: Teachers' principles and classroom practices. Applied Linguistics 22, no. 4: 470-501. doi: 10.1093/applin/22.4.470

Burns, A. 1992. Teacher beliefs and their influence on classroom practice. Prospect 7, no. 3: $56-65$.

Charmaz, K. 2006. Constructing grounded theory: A practical guide through qualitative analysis. Thousand Oaks, CA: Sage Publications.

Clarke, M. 2008. Language teacher identities: Co-constructing discourse and community. Bristol: Multilingual Matters. 
Dewaele, J.-M. and T.M. Al-Saraj. 2015. Foreign language classroom anxiety of Arab learners of English: The effect of personality, linguistic and sociobiographical variables. Studies in Second Language Learning and Teaching 5, no. 2: 205-228. doi: 10.14746/ssllt.2015.5.2.2

Dewaele, J.-M. and P.D. MacIntyre. 2014. The two faces of Janus? Anxiety and enjoyment in the foreign language classroom. Studies in Second Language Learning and Teaching 4, no. 2: 237-272. doi: 10.14746/ssllt.2014.4.2.5

Dewaele, J.-M. and A. Stavans. 2014. The effect of immigration, acculturation and multicompetence on personality profiles of Israeli multilinguals. International Journal of Bilingualism 18, no. 3: 203-221. doi:10.1177/1367006912439941

Dörnyei, Z. 2005. The psychology of the language learner: Individual differences in second language acquisition. Mahwah, NJ: Lawrence Erlbaum.

Dörnyei, Z. and K. Csizér. 1998. Ten commandments for motivating language learners: Results of an empirical study. Language Teaching Research 2, no. 3: 203-229. doi: $10.1177 / 136216889800200303$

Dörnyei, Z. and M. Kubanyiova. 2014. Motivating learners, motivating teachers. Cambridge: Cambridge University Press.

Dörnyei, Z. and T. Murphey. 2003. Group dynamics in the language classroom. Cambridge: Cambridge University Press.

Dörnyei, Z. and S. Ryan. 2015. The psychology of the language learner revisited. New York: Routledge.

Gkonou, C., D. Tatzl and S. Mercer. (Eds.). 2015. New directions in language learning psychology. Dordrecht: Springer.

Golombek, P.R. 1998. A study of language teachers' personal practical knowledge. TESOL Quarterly 32, no. 3: 447-464. doi: 10.2307/3588117

Gregersen, T., P.D. MacIntyre and S. Mercer. (Eds.). forthcoming. Positive psychology in SLA. Bristol: Multilingual Matters.

Gregersen, T., P.D. MacIntyre and M. Meza. 2014. The motion of emotion: Idiodynamic case studies of learners' foreign language anxiety. The Modern Language Journal 98, no. 2: 574-588. doi: 10.1111/modl.12084

Hiver, P. 2013. The interplay between possible language teacher selves in professional development choices. Language Teaching Research 17, no. 2: 210-227. doi: $10.1177 / 1362168813475944$

Johnson, K.E. 1992. The relationship between teachers' beliefs and practices during literacy 
instruction for non-native speakers of English. Journal of Literacy Research 24, no. 1: 83-108. doi: 10.1080/10862969209547763

Kalaja, P., A.M.F. Barcelos, M. Aro and M. Ruohotie-Lyhty. 2016. Beliefs, agency and identity in foreign language learning and teaching. Basingstoke: Palgrave.

Kubanyiova, M. 2014. The knowledge base of language teachers. In Encyclopedia of applied linguistics, ed. C.A. Chapelle, 1-6. Malden, MA: Wiley-Blackwell.

Li, L. 2013. The complexity of language teachers' beliefs and practice: One EFL teacher's theories. The Language Learning Journal 41, no. 2: 175-191. doi: $10.1080 / 09571736.2013 .790132$

MacIntyre, P.D. and S. Mercer. 2014. Introducing positive psychology to SLA. Studies in Second Language Learning and Teaching 4, no. 2: 153-172. doi: 10.14746/ssllt.2014.4.2.2

Mercer, S. and S. Ryan. (Eds.). 2015a. Special Issue of Studies in Second Language Learning and Teaching 5, no. 1.

Mercer, S. and S. Ryan. (Eds.). 2015b. Special Issue of Studies in Second Language Learning and Teaching 5, no. 2.

Mercer, S., S. Ryan and M. Williams. 2012. Introduction. In Psychology for language learning: Insights from research, theory and practice, eds. S. Mercer, S., Ryan and M. Williams, 1-9. Basingstoke: Palgrave Macmillan.

Mercer, S. and M. Williams. (Eds.). 2014. Multiple perspectives on the self in SLA. Bristol: Multilingual Matters.

Murphey, T., J. Falout, Y. Fukada and T. Fukuda. 2012. Group dynamics: Collaborative agency in present communities of imagination. In Psychology for language learning: Insights from research, theory and practice, eds. S. Mercer, S., Ryan and M. Williams, 220-238. Basingstoke: Palgrave Macmillan.

Phipps, S. and S. Borg. 2009. Exploring tensions between teachers' grammar teaching beliefs and practices. System 37, no. 3: 380-390. doi:10.1016/j.system.2009.03.002

Stevick, E.W. 1980. Teaching Languages: A Way and Ways. Rowley, MA: Newbury House.

Tassinari, M.G. 2015. Emotions and feelings in language advising discourse. In New directions in language learning psychology, eds. C. Gkonou, D. Tatzl and S. Mercer, 7196. Dordrecht: Springer.

Varghese, M., B. Morgan, B. Johnston and K.A. Johnson. 2005. Theorising language teacher identity: Three perspectives and beyond. Journal of Language, Identity \& Education 4, no. 1: 21-44. doi: 10.1207/s15327701jlie0401_2 
Williams, M. and R.L. Burden. 1997. Psychology for language teachers: A social constructivist approach. Cambridge: Cambridge University Press.

Williams, M., S. Mercer and S. Ryan. 2015. Exploring psychology in language learning and teaching. Oxford: Oxford University Press.

\footnotetext{
${ }^{1}$ The most illustrative and representative examples were selected for citation purposes.

${ }^{2}$ The numbers in brackets indicate the number of teachers who referred to each strategy.
} 